UDC 62-4.001.2:681.787.7(045)

\title{
NON-CONTACT METHOD OF SURFACE 3D PROFILING
}

NAU Aerospace Institute

Review of interferometric methods of surface analysis. Automatic method of surface 3D profiling is proposed.

\section{Introduction}

White light interferometry is a well-established technique for quickly determining three-dimensional surface shape over large areas.

Systems employing this technique can measure areas as large as the field of view of the instrument, typically up to $15 \mathrm{~mm}$.

As manufacturers move to smaller form factors and more stringent quality controls, the need for fast, reliable surface shape metrology continues to increase.

Applications in semiconductors, data storage, optical telecommunications and Micro Electro Mechanical Systems require surface measurement across large scan areas, with nanometer resolution, to characterize the surfaces of wafers, substrates and individual components.

Several metrology solutions provide either excellent resolution or fast speed. Stylus profiling, for example, offers scans up to hundreds of millimeters in length, but each scan is only one trace wide.

Optical focusing techniques offer reasonable resolution (approximately $10 \mathrm{~nm}$ ) but only acquire data in the range of hundreds of points per section. Techniques such as laser triangulation can be used for non-contact, long scan measurement, but with resolution only on the order of microns. White light interferometry, or white light profiling, is often preferred for its combination of non-contact measurement, repeatable 3D surface measurement, speed, and sub nanometer resolution. This method is employed for surfaces with average roughness down to $0,1 \mathrm{~nm}$ and peak to valley heights up to several millimeters, with repeatability of $0,1 \mathrm{~nm}$ or better.

In the case of specimens such as semiconductors, which are extremely sensitive to contamination, or soft and easily deformed specimens, it is desirable to form an interference pattern without contact [1].

\section{Analysis of existent methods}

So let's consider some types of interferometers such as Michelson interferometer and Linnik interferometer.

The principle of the Michelson interferometer, is illustrated in fig. 1, is quite simple. The essential elements of the design are as follows. A beam emitted by the light source is split into two beams of nearly equal intensity by a half mirror (beam splitter), one of these beams being directed onto a flat reference mirror and the other onto the specimen surface.
The light produced by reflection of these two beams is then made to interfere. When observed from the viewing port, interference occurs between the image of the reference mirror and the image of the specimen surface. Since the light waves reflected by the specimen and the reference mirror originate from the splitting of a beam emitted by the same light source, these waves are mutually coherent, and consequently a two-beam interference pattern is obtained.

The object inserted into the optical path between the beam splitter and the reference mirror, is a glass plate of the same composition and thickness as the beam splitter. Because of the presence of this plate, the two divided light beams arrive at the viewing port after propagating through the equivalent optical distance (the product of refractive index and thickness of the optical components). Note that in this type of interferometer, the beam splitter and specimen surface are separated by an appreciable distance; thus, an interference pattern is obtained without contact.

Another instrument variation is provided by the Linnik interferometer, which utilizes a high magnification objective lens in the application of the interference technique to observation of minute details. The principle employed is that of the Michelson interferometer.

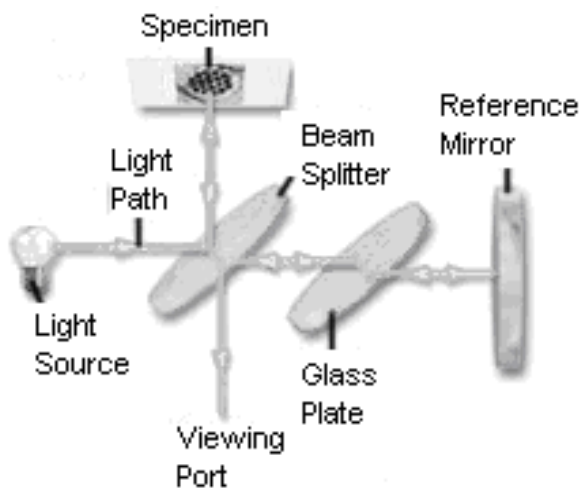

Fig. 1. Scheme of Michelson interferometer

Fig. 2 presents the basic arrangement, comprising a light source, a collimator, a beam-splitting prism, an eyepiece, uniform objective lenses with completely identical optical distances, a specimen surface, which gives rise to an image, and a reference mirror, which gives rise to a reflection image. 


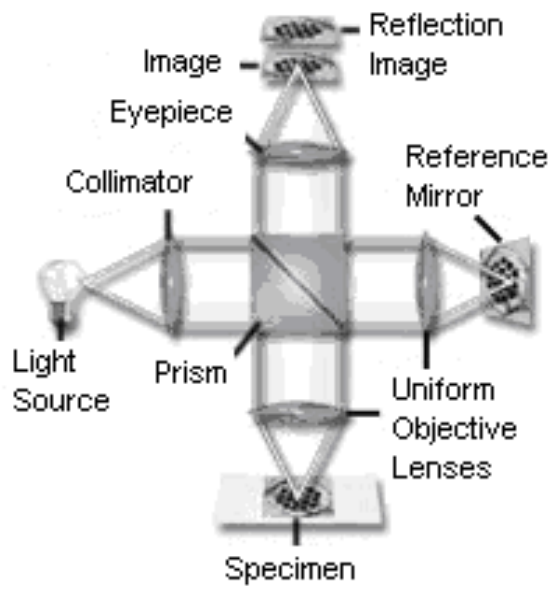

Fig. 2. Scheme of Linnik interferometer

Because uniform objective lenses are difficult to manufacture, only a small number of such instruments have been marketed [2].

The problem is that with the help of these devices we can only estimate height of one point.

With the help interferometer we can observe both interference and real image of specimen. If tested specimen has mound or cavity then in this place propagation difference changes, therefore interference fringes shift. While interference measurements this interference fringe displacement we measure as intervals between interference fringes. Obviously that fringe displacement which is equal to one interval appears while propagation difference onto one wavelength. Let's designate depth of cavity as $H$. Then propagation difference $\Delta$ (fig. 3), which is caused by cavity, is equal $\Delta=2 H$.

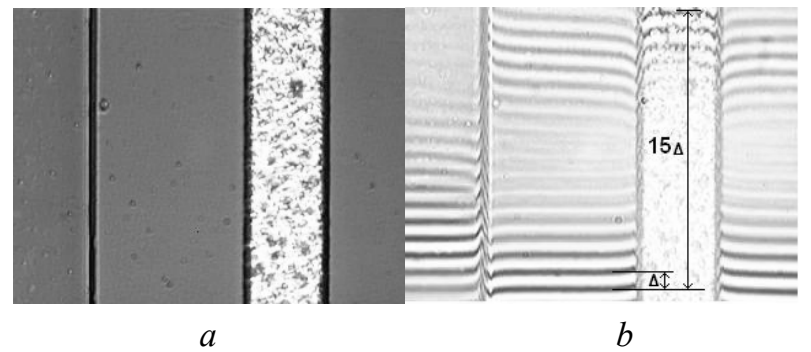

Fig. 3. Real image of microcircuit surface $(a)$, fringe pattern of microcircuit surface $(b)$

It gives interference fringes displacement onto $P$ intervals. While observing in monochromatic light $\Delta=p \lambda$

Obviously, that depth of cavity $H$ is determined by this equation:

$H=p(\lambda / 2)$.

Usually we can evaluate magnitude of interference fringes deformation up to 0,1 of interval between them $(P=0,1)$.

So the least height of cavity which we can determine is equal [3]:

$\mathrm{H}_{\min }=0,05 \lambda$.

For bell light $\lambda=0,54$.

\section{Our proposition}

For automatization of registration process in laboratory of National Aviation University was designed 3D profilometer "Micron-alpha". "Micronalpha" is based on Linnik interferometer. With the help of this device we can observe 2D and 3D topography of surface in real time, estimate characteristics of a surface, observe interference figures both in bell, and in homogeneous light.

The sense of modernization consists in the following (fig. 4): unmovable mirror we transform into movable mirror, which controlled by computer, and integrate digital camera which register minimum and maximum brightness of interference signal.

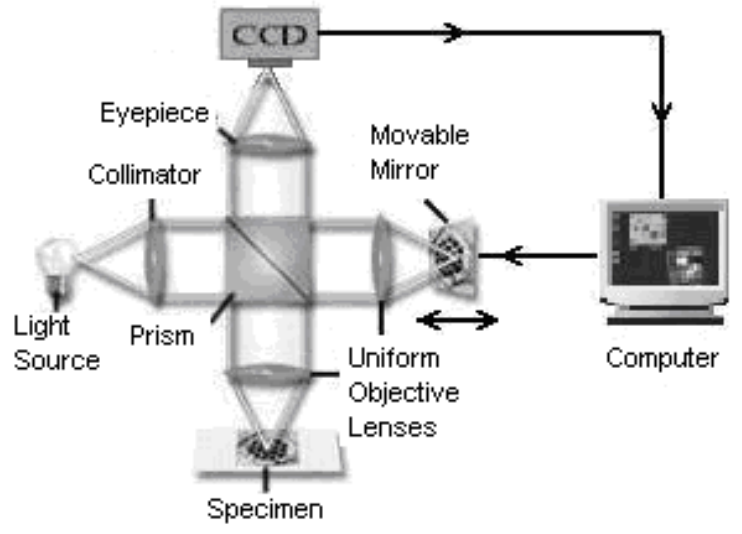

Fig. 4. Scheme of "Micron-alpha"

According to obtained data computer plot 3D topography of surface.

On fig. 5 you can see 3D image of microcircuit surface obtained by "Micron-alpha".

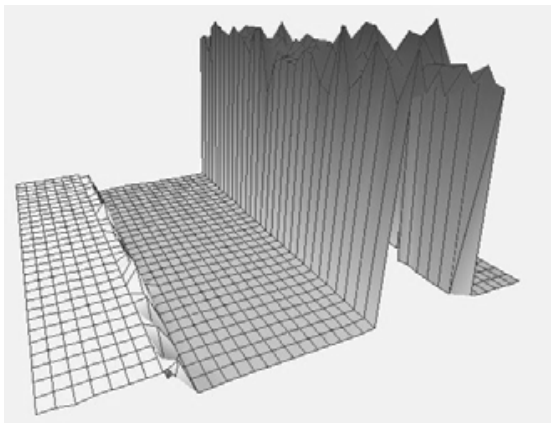

Fig. 5. 3D image of surface obtained

On fig. 6 you can see microscopic image of silicon base shit of a chip.

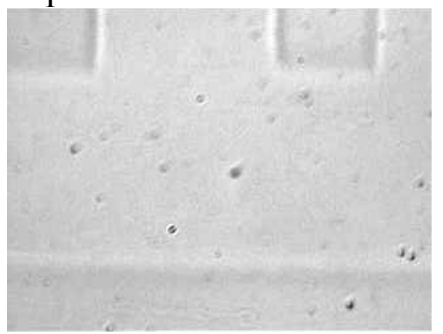

Fig. 6. Microscopic image of silicon base shit of a chip 
On fig. 7 you can see 2D and 3D image of silicon base shit of a chip obtained with the help of "Micron-alpha".
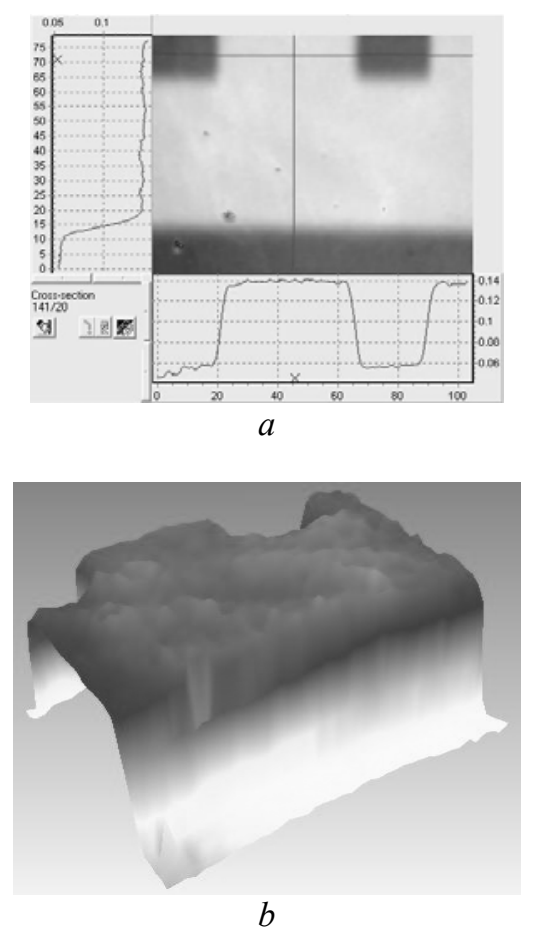

Fig. 7. 2D $(a)$ and 3D (b)image of silicon base shit of a chip

On fig. 8-10 you can see topography of surfaces obtained with the help of "Micron-alpha".

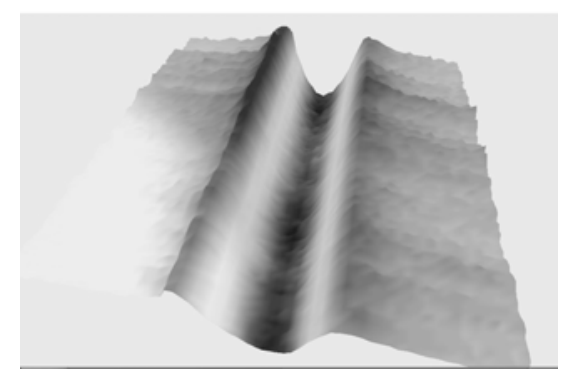

Fig. 8. Micro scratch on steel surface

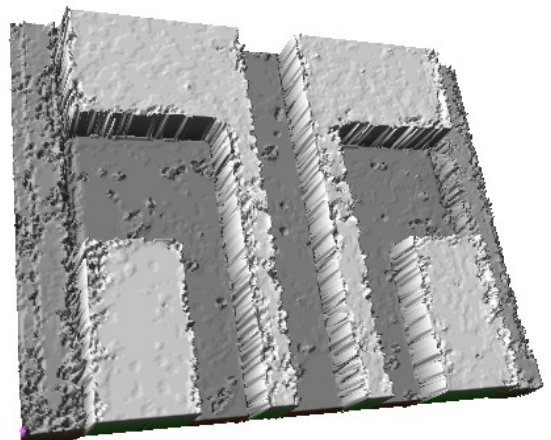

Fig. 9. Tracks of modern microcircuits

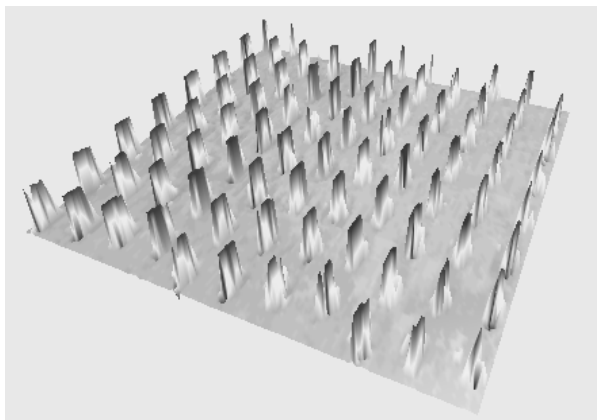

Fig. 10. Surface of CD

\section{Conclusion}

"Micron-alpha" can profile an extremely wide range of surface heights and measure surface features without contact. So it can be successfully applied in non-contact surface 3D profiling.

\section{References}

1. Olszak A.G., Schmit J., Heaton M.G. Interferometry: Technology and Applications, Veeco Instruments, Inc. //www.veeco.com/

2. Hiroshi Komatsu Institute for Materials Research, Tohoku University, Sendai, Japan, Principles and Applications of Two-Beam Interferometry. //www.microscopyu.com/

3. Нагибина И.М., Москалев В.А., Полушкина Н.А., Рудин B.Л. Прикладная физическая оптика ФГУП. - М.: Высш. шк., 2002. - 565 с.

Стаття надійшла до редакції 21.12.05.

\section{B.I. Закієв}

Безконтактний метод тривимірного профілювання поверхні

Розглянуто інтерферометричні методи аналізу поверхні. Запропоновано автоматичний метод безконтактного тривимірного профілювання поверхні.

\section{В.И. Закиев}

Бесконтактный метод трехмерного профилирования поверхности

Рассмотрены интерферометрические методы анализа поверхности. Предложен автоматический метод бесконтактного трехмерного профилирования поверхности. 